\title{
Chemokine and Chemokine Receptor Polymorphisms in Bipolar Disorder
}

\author{
Damla Tokac', Erdem Tuzun², Huseyin Gulec ${ }^{1}$, Vuslat Yılmaz², Elif Sinem Bireller, \\ Bedia Cakmakoglu ${ }^{4}$, and Cem Ismail Kucukali ${ }^{\boxplus}$ \\ ${ }^{1}$ Department of Neurology, Istanbul Erenkoy Psychiatric and Neurological Disorders Hospital, Istanbul, Turkey \\ ${ }^{2}$ Department of Neuroscience, Institute of Experimental Medicine, Istanbul University, Istanbul, Turkey \\ ${ }^{3}$ Department of Pharmaceutical Microbiology, Faculty of Pharmacy, Istanbul Yeni Yuzyil University, Istanbul, Turkey \\ ${ }^{4}$ Department of Molecular Medicine, Institute of Experimental Medicine, Istanbul University, Istanbul, Turkey
}

Objective Bipolar disorder (BD) is a debilitating psychiatric disease with unknown etiology. Recent studies have shown inflammation as a potential contributing factor of BD pathogenesis. However, potential associations between chemokine and chemokine receptor polymorphisms and BD have been fundamentally understudied. To identify participation of chemokines in BD pathogenesis, we examined genetic variants of several chemokine and chemokine receptor genes.

Methods The study population comprised 200 patients with BD and 195 age- and sex-matched healthy controls. Genotyping of monocyte chemotactic protein 1 (MCP-1) A2518G, CCR2 V64I, CCR5 432, CCR5 A55029G, stromal cell-derived factor 1 (SDF-1) 3’A, and CXCR4 C138T polymorphisms was performed using polymerase chain reaction and restriction enzyme digestion.

Results We found that CCR5- $\Delta 32$ II and CXCR4-C138T C+ genotype frequencies contributed to an increased risk for BD. However, no statistical significance could be obtained with these genotypes after Bonferroni correction. A significant asssociation was only found with MCP-1 GG and G+ genotypes, which were markedly more prevalent in patients with BD and these genotypes seemed to significantly increase the risk for BD even after Bonferroni correction.

Conclusion Our findings indicate an association between genetic variants of certain chemokine and chemokine receptor (especially MCP-1) genes and BD. The exact mechanisms by which these variants contribute to BD pathogenesis and their clinical implications need to be further investigated.

Psychiatry Investig 2016;13(5):541-548

Key Words Bipolar disorder, Chemokine receptor polymorphisms, Chemokine, Pathogenesis.

\section{INTRODUCTION}

Bipolar disorder (BD) is one of the most frequent and disabling conditions worldwide. Despite extensive efforts towards optimization of clinical criteria and better understanding of underlying pathogenic mechanisms, little improvement has been achieved in the treatment of BD. Interrelations between neuronal and immunologic systems have long been investigat-

\footnotetext{
Received: August 5, 2015 Revised: January 26, 2016 Accepted: February 12, 2016 Available online: July 11, 2016

$\triangle$ Correspondence: Cem Ismail Kucukali, MD

Department of Neuroscience, Institute of Experimental Medicine, Istanbul University, Istanbul, Turkey

Tel: +90 $2124142000-33325$, Fax: +90 2125324171

E-mail: cemsmile@gmail.com

(a) This is an Open Access article distributed under the terms of the Creative Commons Attribution Non-Commercial License (http://creativecommons.org/licenses/by$\mathrm{nc} / 3.0$ ) which permits unrestricted non-commercial use, distribution, and reproduction in any medium, provided the original work is properly cited.
}

ed and it has now been robustly established that cytokines and other components of adaptive immunity play key roles in host defense against microorganisms and in regulation of neurogenesis, release of neurotransmitters, control of blood-brain barrier permeability, and protection of neurons. ${ }^{1}$ It is therefore not surprising that evidence that indicates involvement of immunity and inflammation in psychiatric disorders including BD is accumulating. ${ }^{2}$

Despite their well-known involvement in neuroimmunologic processes, the pathogenic significance of chemokines, which are small signaling proteins with the ability to induce chemotaxis, has been relatively understudied in BD as compared with other immune system components. In previous studies, expression levels of several chemokine and chemokine receptors have been examined in patients with $\mathrm{BD} .{ }^{1}$ By contrast, potential associations between chemokine and chemokine receptor polymorphisms and $\mathrm{BD}$ have been fundamen- 
tally understudied and only MCP-1 gene polymorphisms have been investigated in patients with $\mathrm{BD} .^{3-6}$

To further delineate the involvement of chemokines in $\mathrm{BD}$ pathogenesis, we compared genetic variants of several chemokines [monocyte chemotactic protein 1 (MCP-1), stromal cellderived factor 1 (SDF-1)] and chemokine receptors (CCR2, CCR5, CXCR4) among healthy control and BD populations and identified chemokine/chemokine receptor genotypes carrying increased risk for $\mathrm{BD}$ development.

\section{METHODS}

\section{Subject selection}

The study sample comprised 200 patients with BD and 195 healthy control subjects with no personal or family history of psychiatric disorders. All patients had active symptoms at the time of the study. Patients and healthy control subjects were recruited from Erenkoy Psychiatric and Neurological Disorders Hospital. Each patient was given a diagnostic assessment based on clinical interviews using a Structured Clinical Interview for Diagnostic and Statistical Manual of Mental Disorders, Fourth Edition (DSM-IV). ${ }^{7}$ Our sample consisted of unrelated patients with $\mathrm{BD}$ (mean age: $40.77 \pm 11.59$; males/ females: 73/127), and 200 unrelated healthy controls (mean age: $42.85 \pm 10.11$; males/females: $84 / 111$ ).

\section{Measurements, protocol, and procedure}

The psychopathologic status of the patients was assessed by two experienced psychiatrists using the Scale for the Assessment of diagnoses in all cases were made based on case records and clinical assessments by consensus of two experienced psychiatrists according to DSM-IV criteria. ${ }^{7}$ All subjects were examined according to a standardized interview. The assessment was performed on a semi-structured sociodemographic form that required patient information regarding demographic personal details of the patients and informants, symptoms of patients, history of present illness, details of medical or surgical interventions, past history, family history, personal history, premorbid personality, details of physical examination, mental status examination, and diagnostic formulation. The diagnosis was made using the Structured Clinical Interview for DSM-IV (SCID-I). ${ }^{8}$ The patients were then screened on various rating scales such as the Brief Psychiatric Rating Scale ${ }^{9,10}$ for patients with BD, and the Rating Scale for Mania ${ }^{11,12}$ for BD. Controls with BD were excluded from the study based on the results of the SCID-I DSM-IV interviews. Normal control participants were recruited from a large medical outpatient clinic. We investigated their demographic data, medical, and psychiatric history.

To minimize the effect of ethnic differences in gene frequen- cies, the study participants were recruited from the Turkish population living in Western Turkey. The study was approved by the Medical Ethics Committee of Istanbul Medical Faculty, and all participants (i.e., controls or patients) gave written informed consent.

\section{Inclusion and exclusion criteria}

Inclusion criteria were a diagnosis of current DSM-IV BD. Patients were excluded if their primary diagnosis was not BD. Patients were also excluded from the study if they had a history of neurologic or medical disorder that would affect neuropsychologic function (i.e., seizures, head trauma, stroke, brain tumor, meningitis) or if they had a recent history of abuse of alcohol or psychoactive drugs. In addition, control subjects were excluded if they had a diagnosis of any DSM-IV axis I and axis II disorders. None of the control subjects had any physical health problems.

\section{Polymorphism analysis}

DNA extraction from white blood cells was completed using the method of Miller et al. ${ }^{13}$ Polymerase chain reaction (PCR)/restriction fragment length polymorphism (RFLP) analysis was performed for the detection of the variations in these region of MCP-1 A2518G, CCR2 V64I, CCR5 $\Delta 32$, CCR5 A55029G, SDF-1 3'A and CXCR4 C138T. ${ }^{14-17}$ PCR was performed using suitable primers listed in Table 1. Products of MCP-1A2518G, CCR2V64I, CCR559029, SDF-1, and CXCR4 were further subjected to digestion with PvuII, BsaBI, SduI, MsPI, and BccI restriction enzymes, respectively. Visualization was completed using electrophoresis through a $3 \%$ agarose gel. The relative size of the PCR products was determined through comparison of the migration of a 50-1000 bp DNA molecular weight ladder (Invitrogen, Grand Island, NY, USA).

\section{Statistical analysis}

Statistical analyses were performed using the SPSS software package version 20.0 (SPSS Inc., Chicago, IL, USA). Data are expressed as means \pm standard deviation (SD). Differences in the distribution of genotypes or alleles between cases and controls were tested using the Chi-square statistic, and comparison of demographic data were tested using Student's t-test. In addition, minor allele frequency and Hardy-Weinberg equilibrium were obtained using Haploview 4.2. Linkage disequilibrium among chemokine gene polymophisms was assessed using D' and $r^{2}$ values obtained through the Haploview program (http://www.broad.mit.edu/mpg/haploview/documentation. php). To control multiple comparisons for 5 polymorphisms, Bonferroni correction was used and $\mathrm{p}<0.01$ was considered statistically significant. 


\section{RESULTS}

Demographic and clinical characteristics of subjects are presented in Table 2. Sex $(p=0.218)$ and age $(p=0.781)$ distribution did not differ significantly between the patients with $\mathrm{BD}$ and healthy controls. The genotypes were not associated with sex, initial symptoms, duration of disease, response to drugs, and clinical psychiatric tests. MCP-1 genotype distribution was significantly different between patients with $\mathrm{BD}$ and healthy controls ( $p=0.009 ; \chi^{2}$ : 9.38) (Table 3). MCP-1 G+ genotype was significantly higher in patients with BD (42\%) as compared with healthy controls (29.7\%) and had higher risk for BD ( $p=0.011, \chi^{2}$ : 6.44; OR: 1.70, 95\% CI: 1.12-2.59). MCP-1 GG genotype incidence was significantly higher in patients with BD (13.5\%) than in controls (5.6\%) and increased the risk of BD ( $\mathrm{p}=0.008, \chi^{2}$ : 7.01; OR: 2.61, 95\% CI: 1.25-5.42). By contrast, MCP-1 AA genotype was significantly higher in healthy controls than in patients with $\mathrm{BD}$ and was associated with reduced disease risk ( $\mathrm{p}=0.011, \chi^{2}: 6.44$; OR: 0.585, 95\% CI: 0.386-0.886). Even after Bonferroni correction, MCP-1 G+ and GG genotypes were significantly associated with increased disease risk $(\mathrm{p}<0.01)$.

CCR5- $\triangle 32$ II genotype frequency was higher (96\%) in the BD group than in healthy control group (91.8\%) without reaching statistical significance and might be associated with increased risk for BD ( $\mathrm{p}=0.080$, Fisher's exact test, OR: 2.145; 95\% CI: 0.89-5.13). Likewise, CXCR4-C138T C+ genotype frequency was higher $(99.5 \%)$ in patients with BD than in controls $(96.9 \%)$ without reaching statistical significance, but might be contributing to increased risk for BD ( $\mathrm{p}=0.057$, Fisher's exact test, OR: 6.31, 95\% CI: 0.754-52.9). There were no differences with regards to CCR2-V64I, CCR5-A55029G, and SDF-1-3'A genotype frequencies between the patients with BD and the healthy control group (Table 3 ).
When allele frequencies were evaluated, CXCR4-C138T genotype C allele and MCP-1-A2518G genotype G allele frequencies were found to be significantly higher in patients with BD than in controls (Table 4). Nevertheless after Bonferroni correction, only MCP-1-A2518G genotype G allele frequency showed statistical significance ( $\mathrm{p}>0.01$ ).

Minor allele frequencies (MAF) are given in Table 5. With the exceptions of CCR5-A55029G and MCP-1-A2518G genotypes, most genotype distributions were found to be consistent with Hardy-Weinberg equilibrium in patients. Among the controls, only SDF-1-3'A and CXCR4-C138T genotype frequencies were consistent with Hardy-Weinberg equilibrium.

Even though GCGGA and ACGGA haplotypes were significantly higher in patients with BD than in controls and GTGGA and GTAGG haplotypes were significantly higher in controls than the patients (Table 6), these differences did not attain statistical significance according to Bonferroni correction.

\section{DISCUSSION}

To understand the underlying pathophysiology of $\mathrm{BD}$, and to discover personalized markers for patients with $\mathrm{BD}$, researchers have worked on several immunologic and inflammatory factors. ${ }^{39}$ These studies have brought several proteins including chemokines and chemokine-related factors to light. ${ }^{40,41}$ Patients with $\mathrm{BD}$ present with exacerbation and remission of symptoms and may clinically be in manic, depressive or euthymic states. These clinical fluctuations are expected to affect gene expression levels. Therefore, not surprisingly, levels of the same chemokine have been found to be increased or reduced in different BD cohorts. ${ }^{1,39,41}$ In some studies performed with patients with BD, serum levels of CXCL10, CCL3, CCL11, and MCP-1 were increased and serum levels of CCL1 and CCL22 were decreased, whereas CCL24 and CXCL8 displayed reduced or in-

Table 1. MCP-1 A2518G, CCR2 V64I, CCR5 $\Delta 32$, CCR5 A55029G, SDF-1 3'A and CXCR4 C138T suitable primers

\begin{tabular}{ll}
\hline Gene frequencies & \multicolumn{1}{c}{ Primers (reverse and forwards) } \\
\hline MCP-1 A-2518G & 5'-TCT CTC ACG CCA GCA CTG ACC-3' \\
CCR2 V64I & 5'-GAG TGT TCA CAT AGG CTT CTG-3' \\
SDF-1 3’A & 5'-CAT TGC AAT CCC AAA GAC CCA CTC-3' \\
& 5'-TTG GTT TTG TGG GCA ACA TGA TGG-3' \\
CXCR4 C-138T & 5'-CAGTCAACCTGGGCAAAGCC-3' \\
& 5'-AGCTTTGGTCCTGAGAGTCC-3' \\
CCR5 Delta32 & 5'-AACTTCCTATGCAAGGCAGT-3' \\
& 5'-TATCTGTCATCTGCCTCACT-3' \\
CCR5 A-55029G & 5'-TGTTTGCGTCTCTCCCAG-3' \\
& 5'CACAGCCCTGTGCCTCTT-3' \\
\hline
\end{tabular}


Table 2. Characteristics of patients with BD and healthy controls

\begin{tabular}{|c|c|c|c|}
\hline & Healthy controls $(\mathrm{N}=195)$ & BD patients $(\mathrm{N}=200)$ & $\mathrm{p}$ value \\
\hline Age, years: mean $\pm S D$ & $42.85 \pm 10.11$ & $40.77 \pm 11.59$ & 0.781 \\
\hline Sex, n (male/female) & $84 / 111$ & $73 / 127$ & 0.218 \\
\hline \multicolumn{4}{|l|}{ Education, \% } \\
\hline $0-5$ years & 21.6 & 43.2 & $<0.001$ \\
\hline $6-11$ years & 29.7 & 29.7 & 0.958 \\
\hline $12-15$ years & 35.1 & 26.6 & 0.090 \\
\hline $16+$ years & 13.5 & 0.5 & $<0.001$ \\
\hline \multicolumn{4}{|l|}{ Alcohol use, $\%$} \\
\hline Yes & NA & 14.1 & NA \\
\hline No & NA & 85.9 & NA \\
\hline \multicolumn{4}{|l|}{ Smoking use, \% } \\
\hline Yes & NA & 58.8 & NA \\
\hline No & NA & 41.2 & NA \\
\hline \multicolumn{4}{|l|}{ Civil status, $\%$} \\
\hline Single & NA & 37.1 & $\mathrm{NA}$ \\
\hline Married & NA & 46.4 & NA \\
\hline Divorced & NA & 16.5 & NA \\
\hline \multicolumn{4}{|l|}{ Relatives marriage, $\%$} \\
\hline Yes & NA & 23.4 & NA \\
\hline No & NA & 76.6 & NA \\
\hline \multicolumn{4}{|c|}{ The degree of closeness of consanguinity, $\%$} \\
\hline 1st degree & NA & 28.6 & NA \\
\hline 2nd degree & NA & 57.1 & NA \\
\hline 3rd degree & NA & 14.3 & NA \\
\hline \multicolumn{4}{|l|}{ Onset of disease, $\%$} \\
\hline$>30$ years & NA & 79.6 & NA \\
\hline$\leq 30$ years & NA & 20.4 & NA \\
\hline \multicolumn{4}{|l|}{ Duration of illness, $\%$} \\
\hline $0-5$ years & NA & 29.4 & NA \\
\hline $6-11$ years & NA & 25.9 & NA \\
\hline $11+$ years & NA & 44.7 & NA \\
\hline \multicolumn{4}{|c|}{ In the course of the disease, $\%$} \\
\hline Mixed & NA & 2.6 & NA \\
\hline Seasonal & NA & 34.9 & NA \\
\hline Rapid cycle & NA & 1.3 & NA \\
\hline Others & NA & 61.2 & NA \\
\hline \multicolumn{4}{|c|}{ Family history of psychiatric illness, $\%$} \\
\hline Schizophrenia & NA & 11.1 & NA \\
\hline Bipolar disease & NA & 67.9 & NA \\
\hline Major depression & NA & 6.2 & NA \\
\hline Others & NA & 14.8 & NA \\
\hline \multicolumn{4}{|l|}{ Medications } \\
\hline No medication & NA & 0.6 & NA \\
\hline Antipsychotic & NA & 59.5 & NA \\
\hline Antidepressant & NA & 14.3 & NA \\
\hline Anticonvulsant & NA & 25.6 & NA \\
\hline
\end{tabular}

NA: not applicable, BD: bipolar disease, SD: standard deviation

544 Psychiatry Investig 2016;13(5):541-548 
creased serum levels in different BD cohorts. In expression studies performed with quantitative RT-PCR, CCL7, CCL20, CXCL2, and MCP-1, gene expressions were upregulated and CCR2 and CX3CR1 gene expressions were downregulated on monocytes, whereas CCL3 gene expression was downregulated on brain samples of patients with BD..$^{1,18-24}$ We hypothesized that polymorphism screening might give a more reflective and profound account of chemokine and chemokine receptor involvement in $\mathrm{BD}$ pathogenesis because polymorphism results are not influenced by clinical fluctuations.
In our polymorphism study, we found significantly increased MCP-1 GG genotype frequency in patients with BD and an increased risk for development of BD in carriers of this genotype. We also found that patients with BD displayed higher frequencies of certain chemokine/chemokine receptor alleles and haplotypes than healthy controls. Overall, our findings confirmed the involvement of chemokines in $\mathrm{BD}$ pathogenesis.

In previous studies, CCR5 and CXCR4 expressions have been shown to be enhanced in patients with major depression in correlation with the severity of clinical findings ${ }^{25}$ and CXCR4

Table 3. Distribution of MCP-1-A2518G, SDF-1-3'A, CCR5-delta32, CCR5-A55029G, CXCR4-C138T and CCR2-V64I gene polymorphisms in patients with bipolar disease (BD) and healthy controls $(C)$

\begin{tabular}{|c|c|c|c|c|c|}
\hline \multirow{2}{*}{ Polymorphism } & \multicolumn{2}{|c|}{ Controls $(\mathrm{N}=195)$} & \multicolumn{2}{|c|}{$\mathrm{BD}(\mathrm{N}=200)$} & \multirow{2}{*}{$\frac{\mathrm{p} \text { value }}{\mathrm{C} \text { vs. } \mathrm{BD}}$} \\
\hline & $\mathrm{N}$ & $\%$ & $\mathrm{~N}$ & $\%$ & \\
\hline \multicolumn{6}{|l|}{ MCP-1-A2518G } \\
\hline AA & 137 & 70.3 & 116 & 58 & 0.009 \\
\hline GG & 11 & 5.6 & 27 & 13.5 & \\
\hline AG & 47 & 24.1 & 57 & 28.5 & \\
\hline \multicolumn{6}{|l|}{ CCR2-V64I } \\
\hline GG & 148 & 75.9 & 141 & 70.5 & 0.200 \\
\hline AA & 8 & 4.1 & 5 & 2.5 & \\
\hline GA & 39 & 20.0 & 54 & 27.0 & \\
\hline \multicolumn{6}{|l|}{ CCR5- $\Delta 32$} \\
\hline II & 179 & 91.8 & 192 & 96.0 & 0.080 \\
\hline $\mathrm{DD}$ & 4 & 2.1 & 0 & 0 & \\
\hline ID & 12 & 6.2 & 8 & 4.0 & \\
\hline \multicolumn{6}{|l|}{ CCR5-A55029G } \\
\hline AA & 90 & 46.2 & 92 & 46.0 & 0.684 \\
\hline GG & 49 & 25.1 & 44 & 22.0 & \\
\hline AG & 56 & 28.7 & 64 & 32.0 & \\
\hline \multicolumn{6}{|l|}{ SDF-1-3'A } \\
\hline GG & 87 & 44.6 & 85 & 42.5 & 0.912 \\
\hline AA & 24 & 12.3 & 26 & 13.0 & \\
\hline AG & 84 & 43.1 & 89 & 44.5 & \\
\hline \multicolumn{6}{|l|}{ CXCR4-C138T } \\
\hline $\mathrm{CC}$ & 150 & 76.9 & 168 & 84.0 & 0.057 \\
\hline TT & 6 & 3.1 & 1 & 0.5 & \\
\hline TC & 39 & 20.0 & 31 & 15.5 & \\
\hline
\end{tabular}

Table 4. Distribution of SDF-1-3'A, CXCR4-C138T, MCP-1-A2518G, CCR2-V64I and CCR5-A55029G allele frequencies in bipolar disease and control groups

\begin{tabular}{llcccc}
\hline & \multicolumn{1}{c}{ SNP } & Associteted alleles & Case, control ratios & Chi square & p value \\
\hline 1 & SDF-1-3'A & A & $0.352,0.338$ & 0.172 & 0.6783 \\
2 & CXCR4-C138T & C & $0.918,0.869$ & 4.842 & 0.0278 \\
3 & MCP-1-A2518G & G & $0.278,0.177$ & 11.354 & $8.10^{-4}$ \\
4 & CCR2-V64I & A & $0.160,0.141$ & 0.556 & 0.456 \\
5 & CCR5-A55029G & A & $0.620,0.605$ & 0.184 & 0.6679 \\
\hline
\end{tabular}


expression alterations have been implicated in brain tissues of patients with $\mathrm{BD}{ }^{26}$ To our knowledge, our study shows an association with MCP-1-A2518G polymorphism and BD for the first time, thus shedding light on $\mathrm{BD}$ pathogenesis. Notably in previous studies, MCP-1-A2518G genotypes have been shown to be related with major depressive disorder but not BD. ${ }^{3-6}$ Our study and previous studies on MCP-1 polymorphism displayed identical diagnostic criteria and demographic features. Therefore, this discrepancy might be due to ethnogeographic differences or different distribution of bipolar type 1 and type 2 patients.

MCP-1 levels have been found to be increased in sera, cerebrospinal fluids, and monocytes of patients with BD. ${ }^{1,18,19,27}$ Moreover, an association has been described between certain MCP-1 genotypes and depressive symptoms or suicide attempts. ${ }^{5,6}$ Thus, our findings together with the previous results, confer a clinical pathogenic role to this specific chemokine. There are a few potential mechanisms through which MCP-1 and other chemokine polymorphisms might influence BP development and severity. The role of inflammation in BD pathogenesis and particularly in cognitive impairment is increasingly recognized. Complex interactions between the central nervous system (CNS) pathogenic microorganism content and inflammation appear to lead ultimately to psychiatric and cognitive impairment. ${ }^{2,28,29}$ Chemokines and chemokine receptors have important actions in the first defense of the host against viral pathogens and altered chemokine expression has particularly been associated with increased CNS viral load. ${ }^{30,31}$ Moreover, MCP-1 regulates Th1 and Th2-type immune responses, which are known to be altered in patienst with BD. ${ }^{32-34}$ Certain MCP1 polymorphisms might presumably alter the functions of this chemokine, leading to increased viral load and a propensity to CNS inflammation, both of which are risk factors for BD. MCP1 modulates neurotransmission by controlling the release of neurotransmitters and plays a neuroprotective role through its anti-apoptotic actions. ${ }^{35-37}$ Most notably, there is evidence to

Table 5. Minor allele frequencies in bipolar disorder patients and controls

\begin{tabular}{lllll}
\hline \multicolumn{1}{c}{ SNP } & Position* & HWpval & Alleles & MAF \\
\hline SDF-1-3'A & 2679288 & 0.5848 & A:G & 0.346 \\
CXCR4-C138T & 41619499 & 0.2705 & T:C & 0.106 \\
MCP-1-A2518G & 7316789 & $2.8 \times 10^{-6}$ & A:G & 0.228 \\
CCR2-V64I & 46347717 & 0.163 & G:A & 0.151 \\
CCR5-A55029G & 46360444 & $1.3 \times 10^{-12}$ & A:G & 0.387 \\
\hline
\end{tabular}

*contig accession number. MAF: minor allele frequency

Table 6. The frequencies of haplotypes of chemokine genes in patients with bipolar disorder and controls

\begin{tabular}{|c|c|c|c|c|c|}
\hline \multirow{2}{*}{ Haplotypes } & \multicolumn{3}{|c|}{ Frequency } & \multirow{2}{*}{ Chi-square } & \multirow{2}{*}{$\mathrm{p}$ value } \\
\hline & Overall & Patients & Controls & & \\
\hline GTGGA & 0.214 & 0.182 & 0.246 & 4.878 & 0.0272 \\
\hline GTGGG & 0.157 & 0.168 & 0.147 & 0.643 & 0.4227 \\
\hline ATGGA & 0.131 & 0.124 & 0.138 & 0.373 & 0.5415 \\
\hline GCGGA & 0.075 & 0.098 & 0.051 & 6.316 & 0.012 \\
\hline ATGGG & 0.068 & 0.077 & 0.059 & 1.019 & 0.3127 \\
\hline GCGGG & 0.062 & 0.065 & 0.058 & 0.197 & 0.6569 \\
\hline ATGAA & 0.044 & 0.042 & 0.045 & 0.027 & 0.8691 \\
\hline GTGAA & 0.034 & 0.033 & 0.035 & 0.018 & 0.8918 \\
\hline ACGGA & 0.031 & 0.044 & 0.019 & 4.114 & 0.0425 \\
\hline GTAGG & 0.028 & 0.014 & 0.042 & 5.965 & 0.0146 \\
\hline GTGAG & 0.027 & 0.022 & 0.032 & 0.751 & 0.3862 \\
\hline GTAGA & 0.022 & 0.017 & 0.027 & 1.029 & 0.3105 \\
\hline ACAGA & 0.021 & 0.018 & 0.024 & 0.383 & 0.5363 \\
\hline GTGAA & 0.014 & 0.022 & 0.006 & 3.424 & 0.0643 \\
\hline ACGGG & 0.013 & 0.014 & 0.012 & 0.055 & 0.8154 \\
\hline ATAGG & 0.012 & 0.006 & 0.018 & 2.238 & 0.1347 \\
\hline
\end{tabular}

SDF-1-3’A, CXCR4-C138T, MCP-1-A2518G, CCR2-V64I, and CCR5-A55029G. D’: 0.296, LOD: 1.29, r²: 0.01 
suggest that MCP-1 adjusts the production of serotonin, a neurotransmitter closely associated with $\mathrm{BD}$, by hyperpolarizing serotonergic raphe neurons in the midbrain. ${ }^{38} \mathrm{MCP}-1$ polymorphisms might thus affect serotonergic transmission and render susceptibility to BD development.

In conclusion, our findings indicate an association between chemokine and chemokine receptor functions and $\mathrm{BD}$. The exact mechanisms by which chemokine and chemokine receptor gene polymorphisms contribute to $\mathrm{BD}$ development and their associations with clinical features of patients need to be further investigated.

\section{Acknowledgments}

The present work was supported by the Research Fund of Istanbul University. Project No: Normal- 42079. We would like to thank Mr. David F. Chapman for English language editing.

\section{REFERENCES}

1. Stuart MJ, Baune BT. Chemokines and chemokine receptors in mood disorders, schizophrenia, and cognitive impairment: a systematic review of biomarker studies. Neurosci Biobehav Rev 2014;42:93-115.

2. Hamdani N, Doukhan R, Kurtlucan O, Tamouza R, Leboyer M. Immunity, inflammation, and bipolar disorder: diagnostic and therapeutic implications. Curr Psychiatry Rep 2013;15:387.

3. Pae CU, Yu HS, Kim TS, Lee CU, Lee SJ, Jun TY, et al. Monocyte chemoattractant protein-1 (MCP1) promoter -2518 polymorphism may confer a susceptibility to major depressive disorder in the Korean population. Psychiatry Res 2004;127:279-281.

4. Roh MS, Lee KY, Joo EJ, Lee N, Kim YS. No association of the MCP-1 promoter A-2518G polymorphism with bipolar disorder in the Korean population. Neurosci Lett 2007;427:1-5.

5. Pae CU, Kim JJ, Yu HS, Lee CU, Lee SJ, Jun TY, et al. Monocyte chemoattractant protein-1 promoter -2518 polymorphism may have an influence on clinical heterogeneity of bipolar I disorder in the Korean population. Neuropsychobiology 2004;49:111-114.

6. Altamura AC, Mundo E, Cattaneo E, Pozzoli S, Dellosso B, Gennarelli $\mathrm{M}$, et al. The MCP-1 gene (SCYA2) and mood disorders: preliminary results of a case-control association study. Neuroimmunomodulation 2010;17:126-131.

7. American Psychiatric Association. Diagnostic and Statistical Manual of Mental Disorders, Fourth Edition, Text Revision (DSM-IV-TR). Arlington: American Psychiatric Publishing; 2000.

8. First MB, Spitzer RL, Williams JBW. Structured Clinical Interview for DSM-IV (SCID-I). Washington DC: American Psychiatric Association; 1997.

9. Overal JE, Gorhan DR. The Brief Psychiatric Rating Scale. Psychol Rep 1962;10:799-812.

10. Ventura J, Nuechterlein KH, Subotnik KL, Gutkind D, Gilbert EA. Symptom dimensions in recent-onset schizophrenia and mania: a principal components analysis of the 24- item Brief Psychiatric Rating Scale. Psychiatry Res 2000;97:129-135.

11. Karadag F, Oral ET, Aran Yalcin F, Erten E. Reliability and validity of Turkish translation of Young Mania Rating Scale. Türk Psikiyatri Derg 2002;13:107-114.

12. Young RC, Bigss JT, Ziegler VE, Meyer DA. A rating scale for mania: reliability, validity, and sensitivity. Br J Psychiatry 1978;133:429-435.

13. Miller SA, Dykes DD, Polesky HF. A simple salting out procedure for extracting DNA from human nucleated cells. Nucleic Acids Res 1988; 16:1215.

14. Narter KF, Agachan B, Sozen S, Cincin ZB, Isbir T. CCR2-64I is a risk factor for development of bladder cancer. Genet Mol Res 2010;9:685692.

15. Srivastava A, Pandey SN, Choudhuri G, Mittal B. CCR5 Delta32 polymorphism: associated with gallbladder cancer susceptibility. Scand J Immunol 2008;67:516-522.

16. Petersen DC, Glashoff RH, Shrestha S, Bergeron J, Laten A, Gold B, et al. Risk for HIV-1 infection associated with a common CXCL12 (SDF1) polymorphism and CXCR4 variation in an African population. J Acquir Immune Defic Syndr 2005;40:521-526.

17. Pemberton NC, Paneesha S, Hiller L, Starczynski J, Hooper L, Pepper C, et al. The SDF-1 G > A polymorphism at position 801 plays no role in multiple myeloma but may contribute to an inferior cause-specific survival in chronic lymphocytic leukemia. Leuk Lymphoma 2006;47: 1239-1244.

18. Bai YM, Su TP, Li CT, Tsai SJ, Chen MH, Tu PC, et al. Comparison of pro-inflammatory cytokines among patients with bipolar disorder and unipolar depression and normal controls. Bipolar Disord 2015;17:269277.

19. Bai YM, Su TP, Tsai SJ, Wen-Fei C, Li CT, Pei-Chi T, et al. Comparison of inflammatory cytokine levels among type I/type II and manic/hypomanic/euthymic/depressive states of bipolar disorder. J Affect Disord 2014;166:187-192.

20. Panizzutti B, Gubert C, Schuh AL, Ferrari P, Bristot G, Fries GR, et al. Increased serum levels of eotaxin/CCL11 in late-stage patients with bipolar disorder: An accelerated aging biomarker? J Affect Disord 2015; 182:64-69.

21. Brietzke E, Kauer-Sant'Anna M, Teixeira AL, Kapczinski F. Abnormalities in serum chemokine levels in euthymic patients with bipolar disorder. Brain Behav Immun 2009;23:1079-1082.

22. Barbosa IG, Rocha NP, Bauer ME, de Miranda AS, Huguet RB, Reis HJ, et al. Chemokines in bipolar disorder: trait or state? Eur Arch Psychiatry Clin Neurosci 2013;263:159-165.

23. Brambilla P, Bellani M, Isola M, Bergami A, Marinelli V, Dusi N, et al. Increased M1/decreased M2 signature and signs of Th1/Th2 shift in chronic patients with bipolar disorder, but not in those with schizophrenia. Transl Psychiatry 2014;4:e406.

24. Nakatani N, Hattori E, Ohnishi T, Dean B, Iwayama Y, Matsumoto I, et al. Genome-wide expression analysis detects eight genes with robust alterations specific to bipolar I disorder: relevance to neuronal network perturbation. Hum Mol Genet 2006;15:1949-1962.

25. Ogłodek EA, Szota A, Just MJ, Moś D, Araszkiewicz A. Comparison of chemokines (CCL-5 and SDF-1), chemokine receptors (CCR-5 and CXCR-4) and IL-6 levels in patients with different severities of depression. Pharmacol Rep 2014;66:920-926.

26. Madison JM, Zhou F, Nigam A, Hussain A, Barker DD, Nehme R, et al. Characterization of bipolar disorder patient-specific induced pluripotent stem cells from a family reveals neurodevelopmental and mRNA expression abnormalities. Mol Psychiatry 2015;20:703-717.

27. Jakobsson J, Bjerke M, Sahebi S, Isgren A, Ekman CJ, Sellgren C, et al. Monocyte and microglial activation in patients with mood-stabilized bipolar disorder. J Psychiatry Neurosci 2015;40:250-258.

28. Dickerson FB, Boronow JJ, Stallings C, Origoni AE, Cole S, Leister F, et al. The catechol O-methyltransferase Val158Met polymorphism and herpes simplex virus type 1 infection are risk factors for cognitive impairment in bipolar disorder: additive gene-environmental effects in a complex human psychiatric disorder. Bipolar Disord 2006;8:124-132.

29. Leboyer M, Soreca I, Scott J, Frye M, Henry C, Tamouza R, et al. Can bipolar disorder be viewed as a multi-system inflammatory disease? J Affect Disord 2012;141:1-10.

30. Monteiro de Almeida S, Letendre S, Zimmerman J, Lazzaretto D, McCutchan A, Ellis R. Dynamics of monocyte chemoattractant protein type one (MCP-1) and HIV viral load in human cerebrospinal fluid and plasma. J Neuroimmunol 2005;169:144-152.

31. Ansari AW, Schmidt RE, Heiken H. Prednisolone mediated suppression of HIV-1 viral load strongly correlates with C-C chemokine CCL2: in 
vivo and in vitro findings. Clin Immunol 2007;125:1-4

32. Liu HC, Yang YY, Chou YM, Chen KP, Shen WW, Leu SJ. Immunologic variables in acute mania of bipolar disorder. J Neuroimmunol 2004;150: 116-122.

33. Gu L, Tseng S, Horner RM, Tam C, Loda M, Rollins BJ. Control of TH2 polarization by the chemokine monocyte chemoattractant protein- 1 . Nature 2000;404:407-411.

34. Daly C, Rollins BJ. Monocyte chemoattractant protein-1 (CCL2) in inflammatory disease and adaptive immunity: therapeutic opportunities and controversies. Microcirculation 2003;10:247-257.

35. Gosselin RD, Varela C, Banisadr G, Mechighel P, Rostene W, Kitabgi P, et al. Constitutive expression of CCR2 chemokine receptor and inhibition by MCP-1/CCL2 of GABA-induced currents in spinal cord neurones. J Neurochem 2005;95:1023-1034.

36. Banisadr G, Gosselin RD, Mechighel P, Kitabgi P, Rostène W, Parsadaniantz SM. Highly regionalized neuronal expression of monocyte chemoattractant protein-1 (MCP-1/CCL2) in rat brain: evidence for its colocalization with neurotransmitters and neuropeptides. J Comp Neurol
2005;489:275-292.

37. Eugenin EA, D’Aversa TG, Lopez L, Calderon TM, Berman JW. MCP-1 (CCL2) protects human neurons and astrocytes from NMDA or HIVtat-induced apoptosis. J Neurochem 2003;85:1299-1311.

38. Cazareth J, Guyon A, Heurteaux C, Chabry J, Petit-Paitel A. Molecular and cellular neuroinflammatory status of mouse brain after systemic lipopolysaccharide challenge: importance of CCR2/CCL2 signaling. J Neuroinflammation 2014;11:132.

39. Leboyer M, Soreca I, Scott J, Frye M, Henry C, Tamouza R, et al. Can bipolar disorder be viewed as a multi-system inflammatory disease? J Affect Disord 2012;141:1-10.

40. Brietzke E, Kauer-Sant'Anna M, Teixeira AL, Kapczinski F. Abnormalities in serum chemokine levels in euthymic patients with bipolar disorder. Brain Behav Immun 2009;23:1079-1082.

41. Padmos RC, Hillegers MH, Knijff EM, Vonk R, Bouvy A, Staal FJ, et al. A discriminating messenger RNA signature for bipolar disorder formed by an aberrant expression of inflammatory genes in monocytes. Arch Gen Psychiatry 2008;65:395-407. 